Diabetologe 2021 · 17:597

https://doi.org/10.1007/s11428-021-00773-5

Online publiziert: 3. Mai 2021

(c) Springer Medizin Verlag GmbH, ein Teil von Springer Nature 2021

(Q)

Check for
updates

Dieser Beitrag wurde erstpubliziert in Diabetologie und Stoffwechsel (2020) 15 (Suppl 1): S263, https://doi.org/10.1055/a-1194-2998. Nachdruck mit freundl. Genehmigung von Georg Thieme Verlag KG
DDG - Deutsche Diabetes Gesellschaft

Berlin, Deutschland

\section{Gesundheits-Pass Diabetes}

\section{DDG-Praxisempfehlungen \\ Download}

Auf der Webseite der Deutschen Diabetes

Gesellschaft (https://www.deutsche-diabetes-

gesellschaft.de/behandlung/leitlinien)

befinden sich alle PDFs zum kostenlosen

Download.
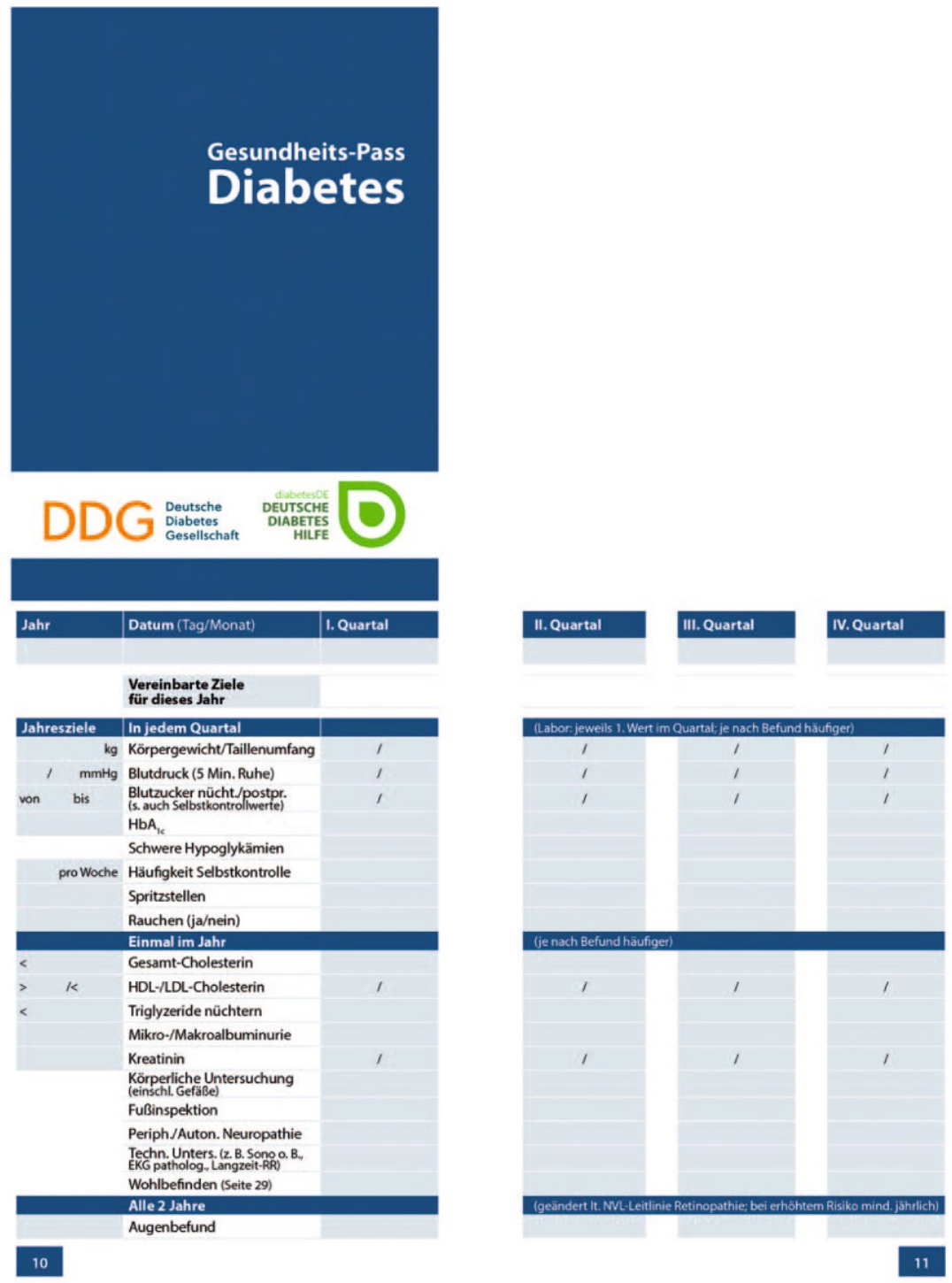

$\Delta$ Seiten 10 und 11 des 31 Seiten umfassenden Gesundheits-Pass Diabetes der Deutschen Diabetes Gesellschaft und der Deutschen Diabetes Hilfe 